\title{
Obligatory dative clitic-doubling of type III experiencers in Bulgnais
}

\author{
Edward J. Rubin*
}

\begin{abstract}
The correlation between the position of the Dative experiencer of a type III psych-verb relative to the verb itself and the obligatory vs. optional nature of an associated Dative clitic has seldom been noted in the literature, and it has never previously been explained. This paper presents relevant new data from Bulgnais (Bologna, Italy), and it proposes that these verbs, in the languages that require the Dative clitic with the preverbal Dative experiencer, have an additional strong lexical property beyond inherent Case licensing. Like Case licensing, this property requires feature checking, which is satisfied alternately by the clitic (unmarked word-order) or by the experiencer phrase. Only when the clitic checks the lexically required feature can the full experiencer move to the preverbal position, because otherwise, it is frozen in a postverbal position by its role in checking the mentioned strong lexical feature, which occurs lower in the verbal domain.
\end{abstract}

Keywords. dative, clitic, experiencer, doubling

1. Introduction. This paper focuses on an explanation of the data presented in (1-2), which are from Bulgnais, a northern Italian variety found in and around Bologna, the capitol of the Emilia-Romagna region of Italy, that has received relatively less attention than other varieties in the country. The pattern below exemplifies an alternation in whether or not a clitic is obligatorily present in an example with an overt, non-clitic, Dative experiencer: ${ }^{1}$
a Żvanén *(a=i=)piès
sti lîber qué
to $\dot{Z}$ SCL=DCL.3=please. $3 \mathrm{SG}$ these books here
"Żvanén likes these books."
La mûsica l'=(i=)é
(sänper) pias̀ò a Żvanén.
the music SCL.F3SG=DCL.3=is always liked to $\dot{Z}$
“Żvanén (always) liked music.'

In (1), the experiencer occupies a preverbal position, which is its unmarked position, and a dative clitic ( $i$ ) is obligatory. On the other hand, (2) shows that an experiencer in a (marked) postverbal position, allows an optional clitic but does not require one. While there are distinct patterns in other grammars, as in Italian, which forbids clitics in both orders, and, as suggested by an anonymous reviewer, in Romanian, which requires the clitic in both orders, the pattern exhibited

\footnotetext{
* I thank my consultants in Bologna very much for their extremely generous help with the data. I would also like to thank the participants at the LSA meeting for their helpful feedback, as well as those at presentations of earlier forms of this work, in the Departments of Linguistics at the University of Utah and the University of Southern California, and at the Going Romance conference in Bucharest. All remaining problems are mine. Edward J. Rubin, Department of Linguistics, University of Utah (e.rubin@utah.edu).

${ }^{1}$ Data in this paper are presented in Ortografia Lessicografica Moderna (Vitali 2005:xi), whose diacritics indicate, for example, voicing (e.g. $\dot{z}=[$ ð ], $z=[\theta]$ ), $\dot{s}=[\mathrm{z}]$, and $s=[\mathrm{s}]$ ), quality/length of stressed vowels (e.g. $e ́=[\mathrm{e}], \hat{e}$ $=[\mathrm{e}:]$ and $\grave{e}=\left[\varepsilon_{\mathrm{r}}\right]$ ), and other distinctions. OLM Conventions concerning the use of blank spaces associated with clitics have been overwritten by the Leipzig glossing rules.
} 
in (1-2) holds at least here and in Peninsular Spanish (as we discuss below) and requires an explanation. ${ }^{2}$

The analysis that we will develop is based on long-standing standard assumptions about the particular verb type involved here which originate in Belletti \& Rizzi (1988), and will not require adoption of the many considerations elaborated in the extensive literature on Clitic-Doubling (see Anagnostopoulou 2005 for a review). Instead, adopting a minimalist approach (Chomsky 2000, 2001, 2008), we will propose (i) that the lexically specified licenser of inherent Dative Case in examples involving such verbs is additionally endowed with a feature related to the alternating position of the experiencer and (ii) that the clitic in such examples may possess this feature (i.e. be able to check the uninterpretable correspondent on the licenser). When the clitic does check the correspondent, it frees the experiencer to move to the preverbal position. Otherwise, the experiencer itself must check that correspondent, and it becomes inactive and frozen in a postverbal position.

The discussion is organized as follows. In the next section, we discuss the analysis of type III psych-verbs in Belletti \& Rizzi (1988), highlighting the uncontroversial aspects that we will adopt from it, including the Inherent Case and preverbal position of the experiencers in Italian, which correspond to the data in (1). In section 3, we note the parallels between our data and that from other grammars noted in discussions of clitic-doubling, concluding that it is not clitic-doubling per se that explains the phenomenon under investigation. In section 4 we explore a previous analysis that proposes to treat the Dative clitic in Spanish data like (1) as a subject clitic, eventually rejecting it as untenable. In the last section, we will provide our analysis of the correlation between the position of the experiencer and the obligatory/optional status of the associated Dative clitic. We will adopt the analysis of inherent Case in Woolford (2006), discuss the feature that we propose is additionally associated with the licenser of inherent case, and demonstrate that all logical possibilities are realized in the observed data.

2. Type III psych-verbs. Belletti \& Rizzi (1988) introduced an analysis of psych-verbs that has had significant impact on subsequent discussions of the theory of argument structure and $\theta$-theory. While our discussion will not need to involve those areas, their basic ideas have held up well, and provide a point of departure for our inquiry into the contrast seen in (1-2). Their proposals distinguished three types of psych-verbs that involve an experiencer argument based on a variety of properties, including the two in (3) and the one in (4) on which we focus in this work.

(3) Types I and II: Examples (1-2) from Belletti \& Rizzi (1988)

a. Gianni teme questo. Gianni fears this

b. Questo preoccupa Gianni. this worries Gianni

\footnotetext{
${ }^{2}$ There are additional aspects of these data that can be observed. First, there is no verbal agreement with the theme (nor experiencer: a nó as piès sti lîber qué 'we like these books') in (1), in contrast to many better-known Romance varieties including Italian and Spanish. There is also a subject clitic (SCL) in (1), and, like the verbal agreement, it does not show agreement (with either argument). This SCL pattern contrasts with the one in (2), where the SLC and verb clearly agree with the preverbal theme. A complete discussion of these agreement issues is not necessary for the main focus of this paper, and I am developing them in other work. See section 5, though, for some further discussion.
} 
(4) Type III: Examples (3) and (111c) from Belletti \& Rizzi (1988)

a. A Gianni piace questo.

to Gianni pleases this

b. Questo piace a Gianni.

this pleases to Gianni

c. *Piace questo a Gianni.

The type III psych-verbs in (4) have an experiencer which may occur either in an unmarked preverbal position, as in (4a), or in a marked postverbal position, as in (4b). Belletti \& Rizzi (1998) say that "the order Experiencer V Theme appears to be unmarked, i.e. the most natural order - the one which does not require contextual justification." Furthermore, they show (4c) that one or the other of the arguments of such verbs must occur in the preverbal position, which does not hold for all other types of verbs in Italian. ${ }^{3}$

Their analysis of (4) proposed that the experiencer is generated in a VP internal position higher than the VP internal theme, and that one or the other moves to the subject position (the higher experiencer in the unmarked order), as seen in (5).

Belletti \& Rizzi (1988)

a. Unmarked Order
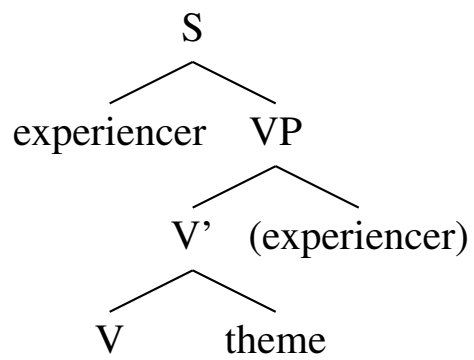

b. Marked Order

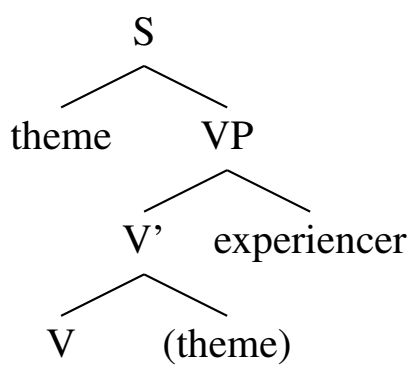

Their analysis includes several important conclusions which we, like most work since then, will adopt here. They note (pg. 334) that the experiencer in such data is "linked to an inherent Case - Dative." Furthermore, they argue that the preverbal experiencer is in the subject position of the clause, and not some other preverbal, left-peripheral position.

One piece of evidence for the preverbal experiencer occupying a subject position is its already noted unmarked status in (4a). Another comes from the contrast seen in (6), their (107):
a. *A nessuno gli hanno detto di andare al diavolo. to nobody to him they said to go to hell
b. ?A nessuno gli piace esser mandato al diavolo. to nobody to him pleases to be sent to hell

\footnotetext{
${ }^{3}$ Their explanation for this requirement centers on the notion of eventive vs. noneventive predicates, with the latter requiring "a nonvacuous predication at S-structure (with a referential subject), while eventive sentences do not have this requirement, and can have all the arguments in the VP at S-structure. (pg. 340)" They further note that if the experiencer is a clitic without a double, this requirement appears to be voided. In descriptive terms, if both arguments are realized as full DPs, one or the other must be preverbal. The facts are clear: something forces the overt movement of one of the two full DP arguments, and does not permit any posited non-overt element in SpecT to satisfy the underlying requirement, including whatever it is that generally permits postverbal subjects in Italian. We return to this issue in section 5 .
} 
In (6a), they note that left-dislocation of an argument is ill-formed when it is a bare quantifier, an idea further discussed in Cinque (1990) et seq. They further note that this judgment contrasts with that for $(6 b)$, where the experiencer argument of the type III verb is preverbal. They conclude that the fronted goal of the intransitive and the fronted experiencer of the type III verb do not occupy the same position, and in particular that the experiencer is not in a left-peripheral position, but in the subject position, as indicated in their tree in (5a).

In (7-8), we see that the same argument holds for data from Bulgnais:

$A=i$ nûster chèp té $t=(i=)$ dè 1 esän̈ni

to=the our bosses you SCL.2SG=DCL.3=have.2SG given the example

"to our bosses, you gave the example."
a. *A inción té $\mathrm{t}=(\mathrm{an}=)(\mathrm{i}=) \mathrm{è}$
détt la veritè
to nobody you SCL.2SG=(NEG=)(DCL.3=)have.2SG told the truth
"to nobody, you told the truth."

b. A inción *(a=i=)piès sti lîber qué

to nobody SCL=DCL.3=please.3SG these books here

"Nobody likes these books."

In (7), the indirect object of a ditransitive is in a clearly left-peripheral, pre-subject position, and its well-formedness contrasts with (8a), because the fronted indirect object here is a bare quantifier, which is, as in Italian, impossible in a left-peripheral position but not in an argument position. When the bare quantifier is a fronted experiencer of a type III psych-verb in Bulgnais (8b), however, the data is well-formed. ${ }^{4}$ We can conclude that the experiencers of type III psych-verbs that we are investigating here do not occupy a left-peripheral position: (8) supports the same argument for Bulgnais as did (6) for Italian.

A lot of work followed from Belletti \& Rizzi's (1988) proposals with a focus on issues of the argument structure of these and other verb types, and on the (structural) properties of their arguments (Pesetsky 1995, inter alia), but we will not need to adopt any of its conclusions to make our arguments in this paper. For our purposes, we need to maintain only the lack of an external argument with type III psych-verbs, the Inherent Case of their experiencer, its location in the subject position when preverbal, and the possibility that either argument of the verb may move there.

3. Clitic-doubling. The presence of the clitic along with the full experiencer in (1) recalls the long-standing inquiry into clitic-doubling in the worlds' languages (see Anagnostopoulou 2005 for a review). A full discussion of the issues explored in the literature is beyond the scope of this work, and, in any case, is not entirely necessary, since Bulgnais is not a clitic-doubling grammar, as we will see below, though it does in this limited context require the clitic along with the full overt argument. Whatever the explanation for the presence of the clitic is, in data like (1), it is not simply the fact of having the underlying properties of a clitic-doubling grammar, however it is

\footnotetext{
${ }^{4}$ The less than perfect status of (6b) contrasts with this equivalent data in Bulgnais in (8b), which is perfectly wellformed. This is presumably due to the presence of the clitic in the Italian example, which is not possible in Italian with type III psych-verbs as it is in Bulgnais, as seen in example (9b) in the text. This difference between Bulgnais and Italian cannot be directly related to the status of these grammars with respect to clitic-doubling, as we see in the next section.
} 
that they, in turn, are conceived.

Consider the contrast between Spanish and Italian in (9):

(9) a. a Juan*(le) gustan estos libros

to $\mathrm{J} \quad$ DCL3s please $3 p$ these books

"Juan likes these books."

b. a Gianni (*gli) piacciono questi libri

to $\mathrm{G} \quad$ DCL3ms please3p these books

"Gianni likes these books."

In Spanish (9a), a preverbal experiencer of a type III psych-verb occurs with the same obligatory Dative clitic as we saw in Bulgnais (1). In Italian (9b), which expands on the data in (4), the clitic is impossible. Data like (9a) is not always mentioned in discussions of (Spanish) clitic-doubling. A general implicit conclusion is that Spanish (and others with similar facts) is a clitic-doubling grammar, while Italian is not, and this is all that needs be said on the contrast above.

Recent work by Nishida (2016), however, demonstrates that the situation is not so simple. Her work proceeds from the observation that there has been little notice at all that Spanish exhibits type III data with a postverbal experiencer and an optional clitic, ${ }^{5}$ like Bulgnais (2). She cites only Demonte (1994) and Vanhoe (2002), both of whom are focused on issues separate from those of interest here. Using data from the Royal Spanish Academy's Corpus de Referencia de Español Actual, she shows that postverbal experiencers are possible in Spanish, and that the clitic may be absent in such examples (i.e. that it is optional with postverbal experiencers), as seen in (10), her example (4).

(10) Les decía, además, que el fútbol $\emptyset$ gusta a los grandes tenores como

Pavarotti, Plácido Domingo y Josep Carreras, ...

"He would tell them, besides, that football appeals to great tenors like

Pavarotti, Placido Domingo and Josep Carreras, ..." ～(La Vanguardia, 17/06/1994)

Spanish, like Bulgnais, shows a correlation between the position of the experiencer and whether or not a Dative clitic is obligatory. Therefore, a claim that Dative clitics are obligatory with Type III psych-verbs in a clitic-doubling grammar is not true, given all the data that Nishida discusses, and it cannot explain why there is this (admittedly rarely noted or discussed) correlation.

Perhaps even more importantly, such a statement will not work for Bulgnais. Consider the

\footnotetext{
${ }^{5}$ For example, Torrego (1998:160) introduces the sort of data in (9a) in the context of a variety of patterns involving experiencers that are possible across Spanish varieties, noting that the type III pattern that we are discussing here is the only version possible in Peninsular Spanish. She does not mention the postverbal experiencer data documented by Nishida (2010). About data like (9a), Torrego (1988) simply states that "the experiencer has to be in the dative, with the dative clitic appearing obligatorily." Her analysis of datives in Spanish and similar grammars is that their Case feature can be checked by transitive verbs, but not by unaccusatives like type III psych-verbs, and that "the dative clitic provides the structure with the Case feature required to check the structural Case feature of the dative complement," and it is therefore obligatory. This analysis, however, cannot be straightforwardly adapted to data with postverbal experiencers, which are presumably also unaccusative and unable to check the Case of the experiencer. When the optional clitic is absent, the data would be incorrectly predicted to be ill-formed. If a null counterpart, or alternative, to the Case checking property ascribed to the clitic in (9a) were posited for data with postverbal experiencers, it should be equally available in (9a), rendering both clitics equally optional (and identical to the optional clitic observed with ditransitive verbs), contrary to fact.
} 
data in (11), which is comparable to the data normally supporting a characterization of a language as having clitic-doubling.
(11) a. ai=ò
vésst Pèvel ajîr
in zänter
$(a i=a$ before $\grave{o})$
SCL.1=have.1SG seen Pèvel yesterday in center
"I saw Pèvel yesterday in the center."
b. *a=l=ò vésst Pèvel ajîr in zänter
SCL.1=ACL.3MSG=have.1SG seen Pèvel yesterday in center
"I saw Pèvel yesterday in the center."

In (11a), a transitive clause contains an animate, specific, definite direct object, and there is no clitic that doubles it in the well-formed example. In (11b), the normal accusative clitic for such direct objects $((a) l)$ is added, and the example is, in contrast, ill-formed. We must furthermore note that there is no preposition (or differential object marker) available in Bulgnais that can render data like (11b) well-formed if it were to occur with the direct object, unlike in grammars that are typically described as clitic-doubling. Like Italian and many others, and unlike Spanish, Romanian, and many others, Bulgnais is not a clitic-doubling grammar (although it does have clitic left-dislocation like other non clitic-doubling grammars, as in (7)). If whatever properties of grammar that determine clitic-doubling were in fact the source of the clitic in type III data with preverbal experiencers in clitic-doubling grammars like Spanish, we would not expect Bulgnais to pattern like them, but, instead, to pattern like otherwise very similar non-clitic-doubling grammars such as Italian. That Bulgnais does pattern like Spanish rather than like Italian thus shows that being a clitic-doubling grammar is not the factor that determines the required presence of the clitic with preverbal experiencers in the data under consideration here. We must seek a distinct explanation for these facts.

4. A previous account. There is one work that specifically addresses the question of the obligatory nature of the Dative clitic with Spanish type III psych-verbs. Montrul (1996) "hypothesize[s] that the obligatory clitic of dative experiencers might also be a phenomenon akin to subject clitic-doubling" in Northern Italian grammars like Fiorentino and Trentino. Essentially, she treats Experiencer clitics in type III Spanish data as subject agreement in AgrS, and contrasts it with "Indirect Object" clitics like those in ditransitive data, which she treats as agreement in AgrIO. Like many others, she does not mention the optionality of the clitic with postverbal experiencers.

Such an analysis cannot be extended to our data from Bulgnais, which is like Fiorentino, Trentino, and many other varieties in the area in having overt subject clitics, including in data like those we are investigating here. (12) presents a full paradigm with the verb viażer 'to travel':

(12) a. (mé) a=viâż

(I) SCL.1=travel.1SG

"I travel."

b. (té) (a)t=viầz

(you) SCL.2SG=travel.2SG

"You travel."

c. (ló/lî́) al/la=viâża

(he/she) SCL.3M/FSG=travel.3SG

"He/She travels." d. (nó) a=viażän

(We) SCL.1=travel.1PL

"we travel."

e. (vó) a=viażè

(you) SCL.2PL=travel.2PL

"You travel"

f. (låur) i/äl=viâżen

(they) SCL.3M/FPL=travel.3PL

"They travel." 
Also like other varieties of the area, Bulgnais exhibits inversion of subject clitics in questions, but not of objects clitics:

(13) a. T=am=al=dè .

SCL.2SG=DCL.1SG=ACL.3MSG=give.2SG

"You are giving it to me."

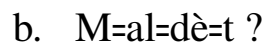

DCL.1SG=ACL.3MSG=give.2SG=SCL.2SG

"Are you giving it to me?"

Let us then consider the following data in which type III verbs occur within questions:

(14) a. Sti lîber qué, *(i=)piaṡrenn=i ?

these books here, DCL.3=like.COND.3PL=SCL.3PL

"These books, would he/she/they like them?"

b. ${ }^{*}(\mathrm{i}=)$ pièṡ=la la ciocolèta ?

(Vitali 2009:121)

DCL.3=like.3SG=SCL.3FSG the chocolate

"Does he/she like chocolate?"

The obligatory Dative clitic of interest here does not invert in questions in (14), distinguishing it from the subject clitics which associate with the theme and do in fact invert. This demonstrates clearly that whatever they are, they are not identical to the subject clitics of this grammar, and are more similar to the Dative clitics observed in ditransitive constructions like in (13). We will not pursue an approach in which there are two distinct subject clitic types, both seen in (14), one of which undergoes the normal inversion for subject clitics in Northern Italian varieties, the other of which doesn't. Instead, in the following section, we will establish an analysis in which all Dative clitics are treated similarly, and are distinct from whatever analysis of subject clitics one assumes.

5. Analysis. As noted above, our analysis starts with four uncontroversial conclusions established by Belletti \& Rizzi (1988): Type III psych-verbs have no external argument; the experiencer is generated in a structurally higher position than the theme; either argument can legitimately move to the subject position, with the noted alternation in the requirement for the clitic in Bulgnais (and Spanish); and the experiencer has Inherent Dative Case.

Let us start with some detail on the notion of Inherent Case. We follow Woolford's (2006) conclusion that so-called nonstructural case comes in two types, which she calls "Lexical" and "Inherent," with the definitions in (15-16) (her examples (4) and (6), respectively):

(15) Two types of nonstructural Case

Lexical Case: Idiosynchratic, lexically selected Case

Inherent Case: Case inherently associated with certain $\theta$-positions

(16) Lexical and Inherent Case licensing

a. Lexical heads (e.g. V, P) license idiosyncratic lexical Case.

b. Little/light v heads license inherent Case.

Note that (16) invokes licensing, a notion normally associated with structural Case, but explicitly ascribed now to "nonstructural" Case. We adopt this idea, following her statement that "all Case licensing is technically structural, in the sense that all Case licensing is done by heads in a local structural configuration. While structural Case is licensed on a purely structural basis, 
nonstructural Case is licensed in connection with $\theta$-marking (Chomsky 1986). (pg. 116)" The structural mechanisms that we will adopt for enacting this notion of licensing will be the standard probe-goal ones of minimalism, applying them equally to structural Case and to the ( $\theta$-related) Inherent Case of experiencers of type III psych-verbs.

In (17), we see Woolford's structure, ${ }^{6}$ which uses applicative light $v$ s, following McGinnis $(1996,1998,2001)$ and much subsequent work:

Woolford's (2006) Structure for Ditransitives

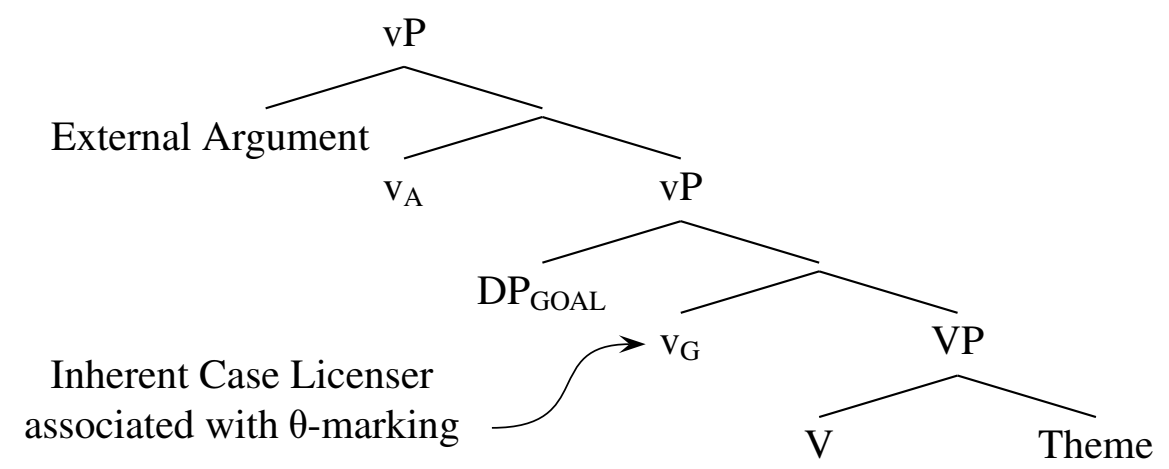

For our purposes, we must make two minor changes to this structure based on our discussions in section 3, to reflect the properties of the type III verbs we are examining here in contrast to the ditransitive data on which Woolford (2006) based (17). First, since type III verbs are intransitive, lacking an external argument, we must remove her $v_{A}\left(=v^{*}\right)$. Second, the particular $\theta$-role involved in our data is not GOAL, but EXPERIENCER, so the particular light $v$ involved must be changed (though it will not impact our analysis at all if these two $\theta$-roles/light $v$ s are considered identical, or if either is related in any way to other $\theta$-roles). These changes are reflected in (18): ${ }^{7}$

Changes to Woolford's (2006) Structure for our data

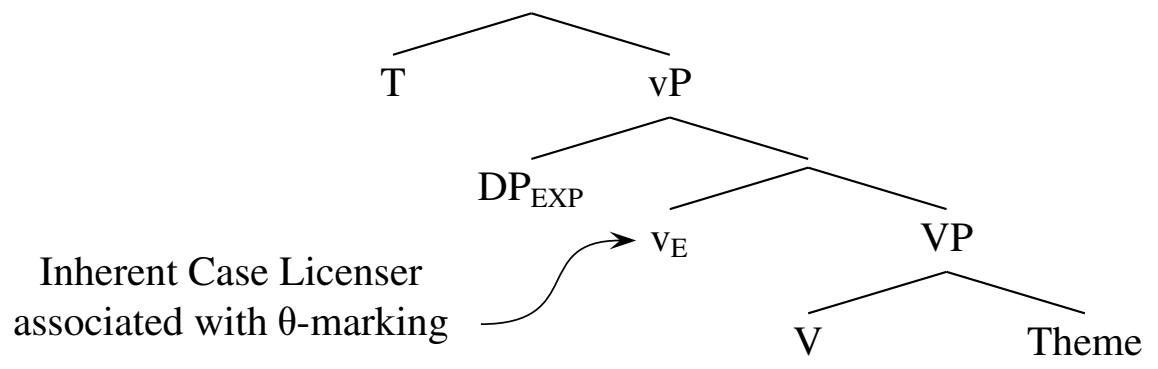

For the observation noted by Belletti \& Rizzi (1988) that either argument of the type III psych-verb in Italian may, and that one must, move to the preverbal subject position, which holds also of Bulgnais, we adopt a standard analysis. Within the minimalist approach we are assuming, all movements are driven by feature checking, with an unvalued feature on a probe seeking its valued correspondent on an active goal. We therefore conclude that $\mathrm{T}$, to whose specifier one or the other argument moves, must have an unvalued feature $\mathrm{uF}$ in need of being checked, and that

\footnotetext{
${ }^{6}$ Note that many other works adopt essentially this same proposal, including Roberts (2010) in his discussion of cliticization with ditransitive verbs (pg. 138) and with inherent possessives of verbs like Spanish doler 'to hurt'.

${ }^{7}$ We should explicitly note that the adoption of light $v$ shells, even for an internal argument like GOAL or EXPERIENCER, is a change from the assumption in Belletti \& Rizzi (1988), standard at that time, that all internal arguments, and thus both arguments of type III verbs, were VP-internal, as seen in (5) in the text.
} 
either argument of the verb (or both, as discussed below) can possess the corresponding feature (bundle) $\mathrm{F}$ that (along with whatever other properties make it active) checks the uF on $\mathrm{T}$ when it moves to SpecT, as represented in (19).

$[\mathrm{uF}]$ on $\mathrm{T}$, which underlies the observed movement of one of the two arguments

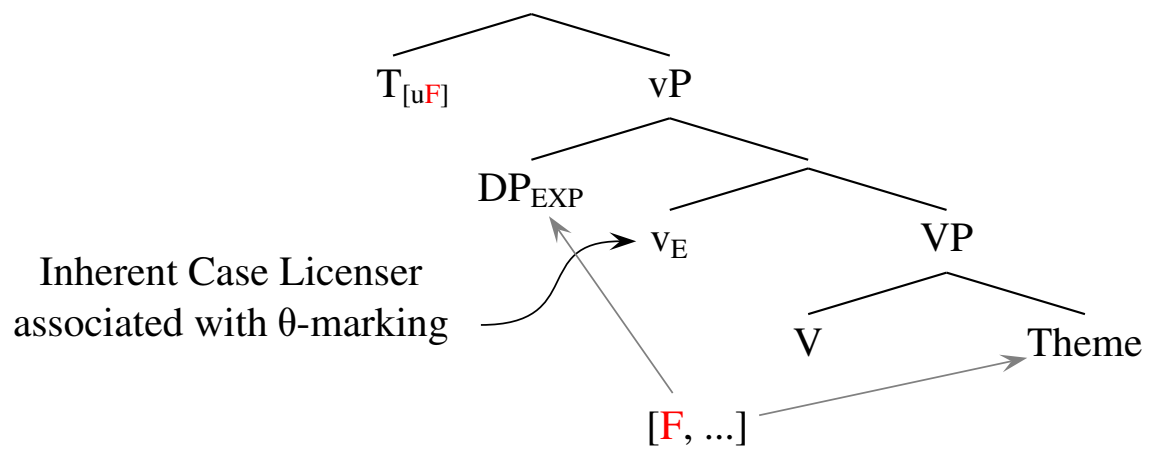

We should note that it is not likely that $\mathrm{uF}$ is simply EPP on T. Both Bulgnais and Italian permit postverbal subjects, and thus nonovert SpecTs, without violation of the EPP, however conceived. Thus, the EPP alone cannot explain the impossibility of a null SpecT in this sort of data.

Moreover, in data involving movement that checks the EPP (of a tensed clause), Case checking is typically also involved. Here, we cannot assume that Case checking is in fact also involved. That is, the Case of either argument is apparently able to be satisfied in situ, so cannot be directly related to need for one or the other of them to move. To be clear, we have assumed that the Inherent Case licensing of $\mathrm{DP}_{\mathrm{EXP}}$ is accomplished at merger, in association with its $\theta$-marking, per Woolford (2006). As evidenced by the possibility for $\mathrm{DP}_{\mathrm{EXP}}$ to remain in an in-situ postverbal position, for example in (2), this Case licensing, like that of the goals of ditransitives discussed in Woolford (2006) and elsewhere, is possible without an association with EPP. It must then be some non-Case-related feature set that underlies its movement to the preverbal position, when it does move. Similarly, the theme must be able to have its Case checked in situ, since the data is well-formed in either order, and the experiencer occupies SpecT when the theme is postverbal. This again casts doubt on analyzing $\mathrm{uF}$ as purely Case-related. In a preverbal position, however, the theme might indeed be having its Case checked in the more usual way, i.e. in association with the checking of overt agreement and EPP in T. For grammars like Spanish or Italian, the same can be held of postverbal themes in such data, e.g. (9), though by long distance checking without movement of the theme (another reason to doubt that $\mathrm{uF}$ is EPP). Such grammars do in fact show agreement between T and the postverbal theme. Even so, Belletti \& Rizzi (1988) showed that the experiencer occupies SpecT in such data, not the theme, and presumably satisfies EPP like an existential expletive. Bulgnais T, however, shows no agreement ${ }^{8}$ with the postverbal theme in

\footnotetext{
8 The lack of agreement with postverbal themes in Bulgnais might furthermore raise problems for the standard assumption that Case licensing necessarily involves (abstract) agreement, at least in the usual sense of the sharing of features between probe and goal that, when reflected overtly, match in their properties. In separate work, I examine this issue, considering several approaches. I explicitly reject any assumption that Bulgnais has two forms of agreement, a more common and morphologically overt one and another, seen only with postverbal subjects and "nominative objects", that does not reflect the agreement features of the goal that it finds but instead appears as a default (3SG). I do explore a form of Belletti's (1988) approach to the Case of postverbal (unaccusative) subjects.

This issue, however, is independent of the concerns of this work, given the identity of the properties of the clitics in both Spanish and Bulgnais, with and without overt agreement with postverbal themes, respectively.
} 
such data as (1) (just as with postverbal subjects in such grammars), though these grammars typically otherwise have strong and rich agreement in T. Thus, neither Case checking nor EPP seem to explain all the movements observed in our data. Something else must be involved, perhaps the factor discussed in footnote 3, and while we need not commit to Belletti \& Rizzi's (1988) account of that factor, nor to any other, we can assume that some such property is at the core of our proposed $(\mathrm{u}) \mathrm{F}$, and provides a standard mechanism for the observed movement given the minimalist framework we have adopted.

With this basic structure and mechanism for movement in place, we are ready to make explicit the two related proposals that will drive our analysis of the basic facts. The first is that, in addition to the Inherent Case licensed by $v_{E}$ that is associated with these type III psych-verbs, the grammars with the clitic patterns under investigation also associate another property with this head: a second $\mathrm{uF}$ (beyond the one on $\mathrm{T}$ ). The second proposal is that, like either of the two full arguments, the Dative clitic in these grammars may also be endowed with the feature(s) F that will permit it to check a uF separately from those arguments. With two uFs in such structures, and three possible locations for the $\mathrm{F}$ that can check them, the full range of observed data will be captured.

It is immediately apparent that a derivation in which all three possibilities for the location of $\mathrm{F}$ are actually realized will necessarily result in a crash, since whatever component of $\mathrm{F}$ it is that makes it active will remain unchecked in one of them because, given the standard nature of checking, the two uFs required in such structures are insufficient for matching all three Fs. In addition, in any derivation in which one or none of the three possible locations of $F$ is realized is equally impossible, as one or the other of the two required uFs will remain unchecked. Let us therefore now consider the full range of possible structures in which two Fs are available for matching with the two required $\mathrm{uFs}$.

In (20) below, we see the structure for examples with the preverbal experiencer, as in (1), which we repeat for convenience. ${ }^{9}$

\footnotetext{
${ }^{9}$ In (20) and the subsequent structures, we ignore movement of the verb, and we represent the experiencer and an associated clitic as a big DP, following Uriagareka (1995, et seq). Variations of the details of such a structure are possible, including those in (i-ii):
}

(i) Torrego $(1998: 160)$

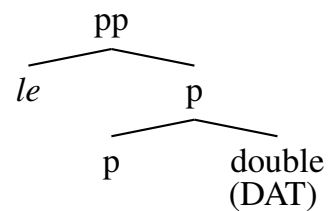

(ii) Roberts (2010:138)

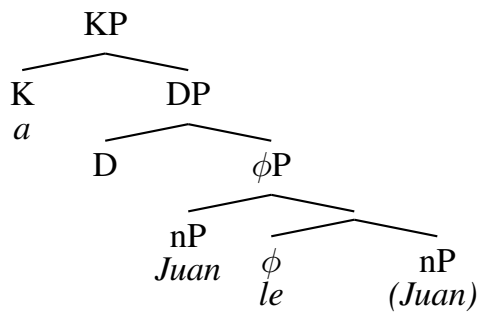

In (i), we see the relevant piece of the structure that Torrego (1998) assumes for type III psych-predicates in Spanish. This constituent occupies the specifier of the VP in her analysis. In (ii), we see Roberts' (2010) representation for an example involving an inalienable possessor and its obligatory clitic that are associated with the Spanish verb doler 'to hurt', which is intransitive and very similar to type III psych-verbs. (ii) occupies the specifier of a light $v$, as in our discussion (though with interesting complications not of direct impact here). As with most such treatments in the literature on clitic-doubling, there are mechanisms proposed in each work for cliticization and the actual placement of the clitic on a verbal head. Our discussion in the text is independent of any particular choice among such analyses. 
(1) a Żvanén *(a=i=)piès sti lîber qué

to $\dot{Z} \quad$ SCL=DCL.3=please.3SG these books here

"Żvanén likes these books."

(20) F on DCL and Experiencer, Preverbal Experiencer

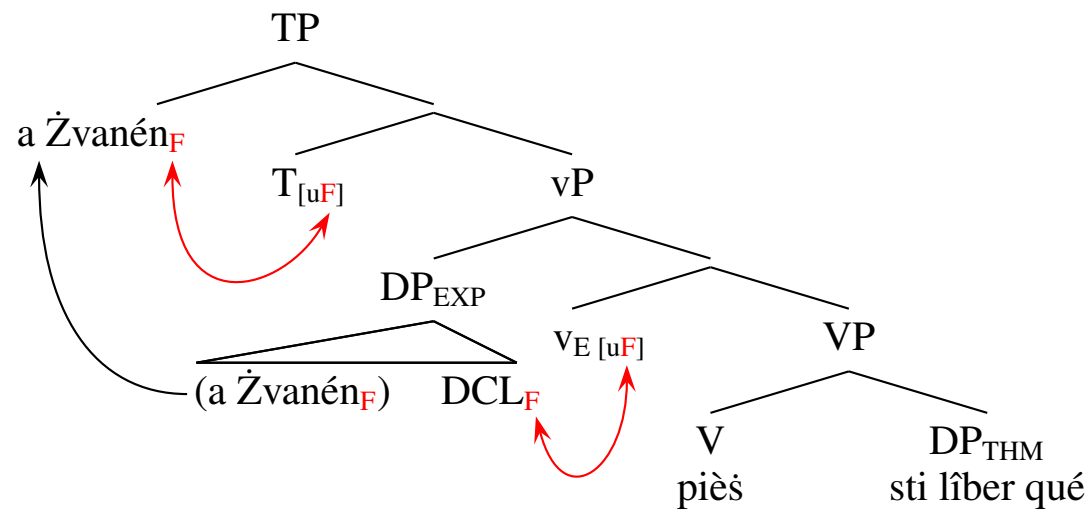

In this structure, the $\mathrm{uF}$ on $\mathrm{T}$ and the one on $v_{E}$ are checked, respectively, by $\mathrm{F}$ on the full experiencer and on the clitic (indicated by red arrows). The theme is not endowed with $\mathrm{F}$. The $\mathrm{uF}$ on $v_{E}$ is checked by the $\mathrm{F}$ on the clitic at merger, when the Inherent Case of the $\mathrm{DP}_{\mathrm{EXP}}$ is also licensed by feature checking. In this situation, the full experiencer (with F) is freed up to move to SpecT where it can check the $\mathrm{uF}$ on $\mathrm{T}$. This possibility is generally unavailable in the following derivations, as we will see.

For the basic facts in (2), repeated below, where there is a postverbal experiencer and a preverbal theme and the Dative clitic is optional, there are three possible structures that arise from the remaining logical possibilities for the distribution of the feature set that can check uF. In (21) below, we see the structure in which there is no clitic, and thus each of the two arguments of the type III verb must have $\mathrm{F}$ or the derivation will crash due to an unchecked $\mathrm{uF}$ (on either T or $v_{E}$ ).
La mûsica l'=(i=)é (sänper) pias̀ò a Żvanén.

the music SCL.F3SG=DCL.3=is always liked to $\dot{Z}$

“Żvanén (always) liked music.'

(21) No Clitic: F on Experiencer and Theme, Postverbal Experiencer

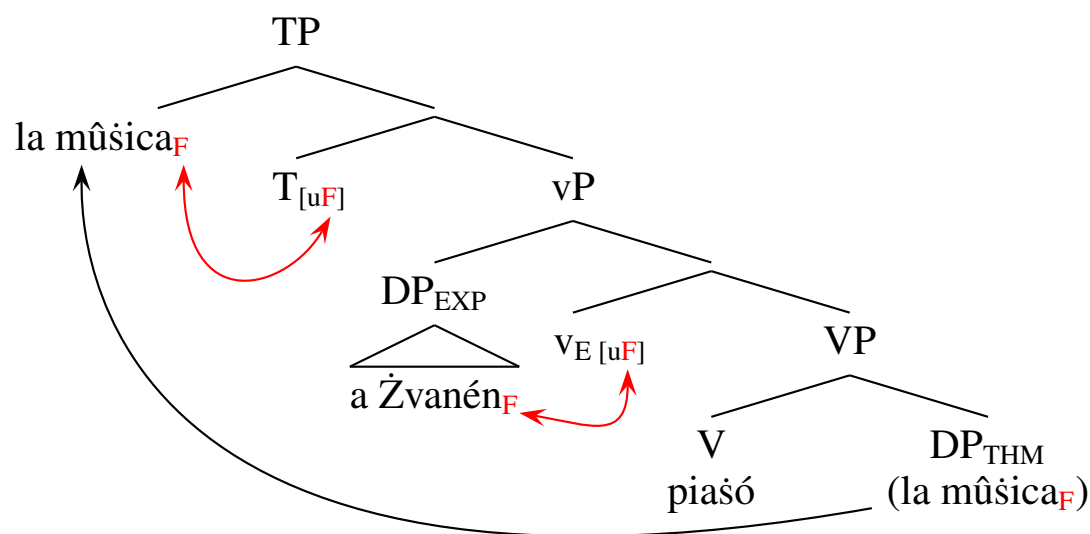

At the merger of $\mathrm{DP}_{\mathrm{EXP}}$, in addition to the checking of its Inherent Dative Case by the relevant 
features on $v_{E}$, there also occurs the checking of the $\mathrm{uF}$ on $v_{E}$ by $\mathrm{F}$ on the full experiencer, which here is the full content of $\mathrm{DP}_{\mathrm{EXP}}$. Since $\mathrm{DP}_{\mathrm{EXP}}$ is now inactive, $\mathrm{DP}_{\mathrm{THM}}$ moves to SpecT and its $\mathrm{F}$ checks uF on $\mathrm{T}$.

We should note a theoretical concern for (the lack of) an intervention effect here. The facts are clear: either argument can surface in the preverbal subject position. Unless the variation in word orders in data like (1-2) in Bulgnais, (4) in Italian, and (9a) vs. (10) in Spanish are due to differing initial merge relations of the two arguments of the type III psych-verbs in each of these grammars, then one or the other of the arguments (the theme under our analysis and in Belletti \& Rizzi's 1988 original) seems to be able to raise past the other in reaching that position, and no intervention effect arises. While there has been debate about the nature of the $\theta$-roles involved among different types of psych-verbs, there has not arisen a similar proposal to subdivide this particular type of psych-verb along similar lines, and we will not make such a proposal here. Note also that Torrego (1998) addresses this lack of intervention effect in her discussion of Spanish type III psych-verbs at the point mentioned in footnote 5, in the context of the agreement between $\mathrm{T}$ and the postverbal theme in Spanish (9a). The well-formedness of such data contrasts with examples of subject-to-subject raising over a Dative experiencer, where she argues that a similar intervention causes ill-fomedness. She holds that the difference arises because "the experiencer argument of psych verbs is an object and the experiencer of raising verbs such as seem is a subject." (See her example (35) on pg. 156 for details concerning this last claim.) Bruening (2014) also provides discussion that calls into question the existence of defective intervention, and we will follow such proposals in seeing this data, and our analysis of it, as non-problematic with respect to such concerns. Still, the hierarchically longer movement of the theme may underlie its marked status relative to the preverbal experiencer.

In (22), we have essentially the same analysis as in (21) above, except that a clitic appears together with the full experiencer in a Big DP. Like above, it is the full experiencer and the theme that bear F, and not the clitic (or there would be too many active elements, leading to a crash).

Optional Clitic: F on Experiencer and Theme, Postverbal Experiencer

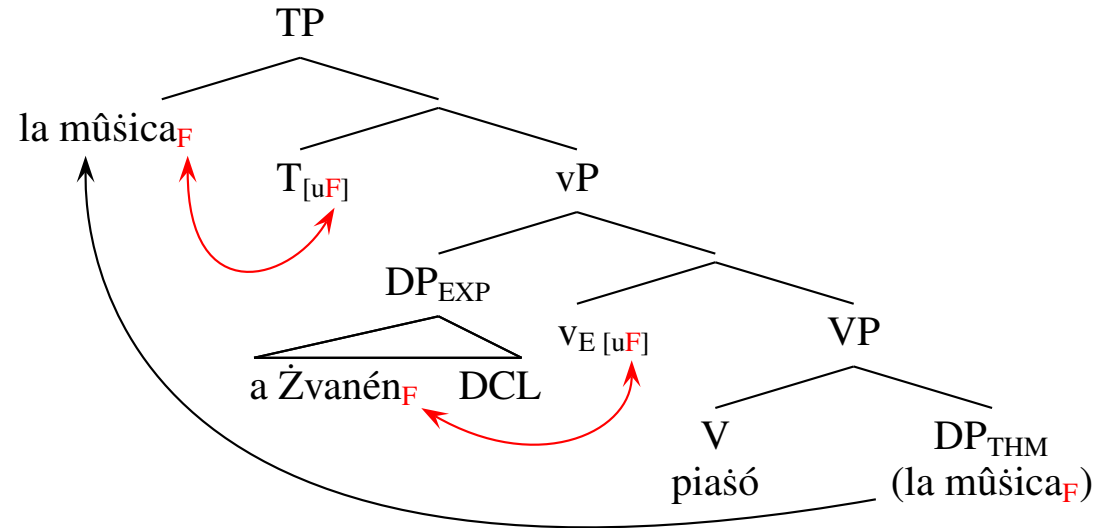

Again as above, when $\mathrm{DP}_{\mathrm{EXP}}$ merges its Inherent Dative Case is checked by features of $v_{E}$ and, simultaneously, the $\mathrm{uF}$ on $v_{E}$ is checked by $\mathrm{F}$ on the full experiencer. Here, in contrast to (21), the clitic is also part of the merged $\mathrm{DP}_{\mathrm{EXP}}$, but, lacking $\mathrm{F}$, it plays no role in the checking of the lexically specified $\mathrm{uF}$ on $v_{E}$, This last point is in contrast to (20), with the preverbal experiencer, where it was indeed the clitic that was responsible for checking $\mathrm{uF}$ on $v_{E}$. 
Finally, in (23) we see the last logical possibility, where F occurs on the clitic and on the theme.

(23) F on DCL and Theme, Postverbal Experiencer

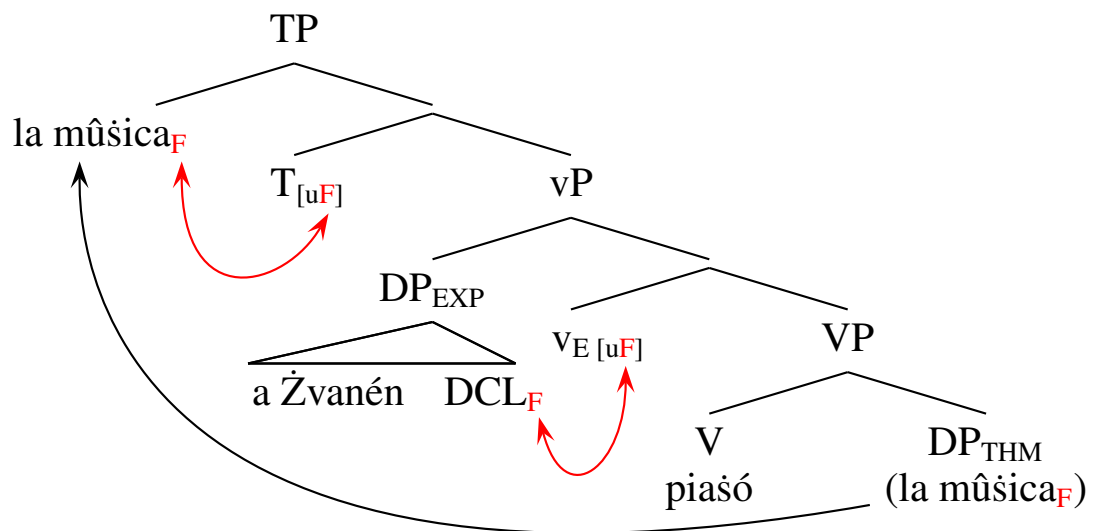

As in (20), it is the $\mathrm{F}$ on the clitic that is responsible for checking $\mathrm{uF}$ on $v_{E}$, though here there is no $\mathrm{F}$ on the full experiencer. Instead, F occurs on the theme, and it raises past the experiencer to check the $\mathrm{uF}$ on $\mathrm{T}$.

6. Summary and Conclusions. In Bulgnais and other grammars like it, including at least Spanish, type III psych-verbs have a required Dative clitic when their experiencer argument is preverbal but an optional one when it is postverbal. To account for this previously unexplained correlation, we have proposed that these verbs lexically specify not only Inherent Dative Case but also an additional feature in need of checking $(\mathrm{uF})$, and that these two properties are associated with the same independently motivated light $v_{E}$. uF is identical to the non-Case-related, non-left-peripheral feature responsible for movement of one of the two arguments to SpecT. At the merger of the experiencer, both properties of the light $v_{E}$, Inherent Case and $\mathrm{uF}$, are simultaneous satisfied by feature checking, a simple extension of Woolford's (2006) notion that Inherent Case is structurally licensed in association with $\theta$-marking. We furthermore proposed that the Dative clitic, like the full arguments independently, can check uF. Such grammars contrast with that of, for example, Italian, which lexically specify Inherent Dative Case but not the additional $\mathrm{uF}$ on the $v_{E}$ of type III verbs.

With two required instances of $\mathrm{uF}$, one on $\mathrm{T}$ and one on $v_{E}$, and with three potential locations for the feature bundle that checks them, on the theme, the experiencer, or the clitic associated with the experiencer, Bulgnais structures containing Type III psych-verbs show the patterns exemplified above in (20-23). The last three examples all show the marked word order with a preverbal theme that possesses the $\mathrm{F}$ that permits it to move to SpecT to check the $\mathrm{uF}$ there, as required for convergence. In (21), there is no clitic, so F necessarily occurs on the full experiencer which checks $\mathrm{uF}$ on $v_{E}$ at merger, when its own Inherent Dative Case is checked. In (22), the optional clitic is present, but does not bear F, and the experiencer once again checks $\mathrm{uF}$ on $v_{E}$ at merger along with Case. In (23), the optional clitic instead does bear F, permitting the checking of its correspondent on $v_{E}$ at merger, but here the full experiencer does not bear F. As noted, $\mathrm{F}$ on the theme requires it to move to SpecT to check uF on T. In all these cases, the theme is preverbal, and the presence of the clitic appears optional because either it or the full experiencer can check uF on $v_{E}$. When the full experiencer does so, the clitic need not even 
appear at all.

It is only as shown in (20), the first of the logical possibilities discussed, that a preverbal experiencer is possible. To be preverbal, it must be attracted to SpecT by uF on T, as the theme was in the other examples. It must therefore bear the corresponding feature set F. However, the experiencer must remain active in order to be attracted to SpecT, and thus the clitic must, at the point of the merger of the two of them to the $v_{E} P$, be available and endowed with the $\mathrm{F}$ that can check the $\mathrm{uF}$ on $v_{E}$. In summary, only when the clitic checks $\mathrm{uF}$ on $v_{E}$ is the experiencer freed to move to a preverbal position, and thus the clitic is obligatory with preverbal experiencers.

\section{References}

Anagnostopoulou, Elena. 2005. Clitic Doubling. In Martin Everaert \& Henk van Riemsdijk (eds.), The Blackwell Companion to Syntax, Volume 1. 519-581. Malden: Blackwell.

Belletti, Adriana. 1988. The Case of Unaccusatives. Linguistic Inquiry 19(1). 1-34.

Belletti, Adriana \& Luigi Rizzi. 1988. Psych-Verbs and $\theta$-Theory. Natural Language and Linguistic Theory 6(3). 291-352.

Bruening, Benjamin. 2014. Defects of Defective Intervention. Linguistic Inquiry 45(4). 707-719.

Chomsky, Noam. 1982. Some Concepts and Consequences of the Theory of Government and Binding. Cambridge: MIT Press.

Chomsky, Noam. 1995. The Minimalist Program. Cambridge: MIT Press.

Chomsky, Noam. 2000. Minimalist Inquiries: The Framework. In Roger Martin, David Michaels \& Juan Uriagereka (eds.), Step by Step: Essays on Minimalist Syntax in Honor of Howard Lasnik. 89-155. Cambridge: MIT Press.

Chomsky, Noam. 2001. Derivation by Phase. In Michael Kenstowicz (ed.), Ken Hale: A Life in Linguage. 1-52. Cambridge: MIT Press.

Chomsky, Noam. 2008. On Phases. In Robert Freidin, Carlos Otero \& Maria-Luisa Zubizarreta (eds.), Foundational Issues in Linguistics Theory: Essays in Honor of Jean-Roger Vergnaud. 133-166. Cambridge: MIT Press.

Demonte, Violeta. 1994. Teoría sintáctica. Madrid: Síntesis.

Holmberg, Anders. 2005. Is There a Little pro? Evidence from Finnish. Linguistic Inquiry 36(4). 533-564.

Kayne, Richard. 1984. Connectedness and Binary Branching. Dordrecht: Foris.

Manzini, Maria Rita \& Leonardo Savoia. 2005. I dialetti italiani e romanci. Alessandria: Edizioni dell'Orso.

McGinnis, Martha. 1996. Projection and position. In João Costa, Rob Goedemans \& Reuben van der Vijver (eds.), Proceedings of ConSole IV. 203-220. Leiden: HIL.

McGinnis, Martha. 1998. Case and locality in L-syntax: Evidence from Georgian. In Heidi Harley (ed.), Papers from the UPenn/MIT Roundtable on Argument Structure and Aspect: MIT Working Papers in Linguistics 32. 139-158. Cambridge: MIT, Department of Linguistics and Philosophy.

McGinnis, Martha. 2001. Semantic and morphological restrictions in experiencer predicates. In John T. Jensen and Gerard van Herk (eds.), Proceedings of the 2000 CLA Annual Conference. 245-256. Ottawa: University of Ottawa, Department of Linguistics, Cahiers Linguistiques d'Ottawa. 
Montrul, Silvina. 1996. Clitic Doubled Dative "Subjects" in Spanish. In Karen Zagona (ed.), Grammatical Theory and Romance Languages: Selected Papers From LSRL XXV. 183-195. Amsterdam: John Benjamins.

Nishida, Chiyo. 2016. IO realization variation in Spanish reverse psych verb sentences. In Thierry Ruchot \& Pascale Van Praet (eds.), Atypical predicate-argument relations. 61-85. Amsterdam: John Benjamins.

Pesetsky, David. 1995. Zero Syntax: Experiencers and Cascades. Cambridge: MIT Press.

Roberts, Ian. 2010. Agreement and Head Movement: Clitics, Incorporation, and Defective Goals. Cambridge: MIT Press.

Torrego, Esther. 1998. The Dependencies of Objects. Cambridge: MIT Press.

Uriagareka, Juan. 1995. Aspects of the syntax of clitic placement in Western Romance. Linguistic Inquiry 26(1). 79-124.

Vanhoe, Henk. 2002. Aspects of the syntax of psychological verbs in Spanish. In Miriam Butt and Tracy Holloway King (eds.), Proceedings of the LFG02 Conference. 378-389. Stanford: CSLI Publication.

Vitali, Daniele. 2009. Dscårret in bulgnaiș? Bologna: Gruppo Perdisa Editore/Airplane srl. Woolford, Ellen. 2006. Lexical Case, Inherent Case, and Argument Structure. Linguistic Inquiry 37(1). 111-130. 